\title{
THE CONTOUR OF THE SUBVALVAR PRESSURE CURVE IN SUBAORTIC STENOSIS
}

\author{
BY \\ SPYROS STAVROPOULOS AND HYWEL DAVIES
}

From the Cardiac Department, Guy's Hospital, London S.E.1

Received October 2, 1964

In making the distinction between the muscular and discrete types of subvalvar aortic stenosis the assessment of the hæmodynamic data is vital, but the criteria are unsatisfactory in a number of cases.

Most reports dealing with the hæmodynamic features (Brachfeld and Gorlin, 1959; Goodwin et al., 1960; Hancock, 1961; Boiteau and Allenstein, 1961; Brockenbrough, Braunwald, and Morrow, 1961; Boiteau, Bourassa, and Allenstein, 1963; Braunwald et al., 1963; Wigle, 1963) emphasize the value of the peripheral arterial wave form in differentiating between the two varieties of subvalvar aortic stenosis. The purpose of this paper is to emphasize the value of critical analysis of the contour of the pressure tracing from the subvalvar chamber in distinguishing between the various types of subaortic stenosis.

\section{SuBJECTS AND MEtHods}

The hæmodynamic data from all the patients with subvalvar aortic stenosis studied in this unit during the past six years were reviewed. There were 30 with hæmodynamic data, and tracings from the subvalvar zone had been obtained in 25 . We are concerned here only with the patients in whom the diagnosis has been confirmed by open-heart surgery or necropsy (14 patients) or where the weight of evidence makes it indubitable that the lesion is of the type described ( 2 patients). The latter, Cases 2 and 6 , show the classical signs of muscular subaortic stenosis, and are members of a family in whom 4 out of 5 sibs are affected, as well as the mother.

There were 6 patients with muscular subaortic stenosis, 4 male and 2 female, ranging in age between 14 and 44 years. Amongst the 10 with the discrete type of lesion there were 6 male and 4 female patients, the age range being 7 to 30 years (Table).

Studies of the left heart have been performed in 6 patients (Cases $2,3,4,5,6,12$ ) by percutaneous femoral or brachial puncture (Seldinger's retrograde technique, using P.E. 160 catheter, 1953) and in 10 patients (Cases 1, 7, 8, 9, 10,11,13,14,15, 16) by anterior percutaneous left ventricular puncture (Brock, Milstein, and Ross, 1956). Inductance (N.E.P.) or strain gauge manometers (Statham) were used and tracings recorded photographically (N.E.P. Recorder-Type 1000).

Aortic pressure tracings were available in all patients. Peripheral arterial records were obtained in all except Case 3 in whom the tracing was too damped to be useful. In the others the following features were analysed:

(1) Rate of rise of pressure in $\mathrm{mm} . \mathrm{Hg} / \mathrm{sec}$. from the beginning of systole to the percussion wave; (2) the systolic upstroke time to the highest peak (SUT), the value being corrected for heart rate by dividing by the square root of the cycle length (Wood, 1958).

In the subvalvar tracings the rate of rise to the initial peak and the systolic upstroke time to the highest pressure have been measured. In the left ventricle the rate of initial rise of pressure has been evaluated.

\section{RESULTS}

Clinical and hæmodynamic details of the patients studied are shown in the Table.

The findings in the peripheral artery, the aortic root, and the subvalvar chamber will be described under the respective headings.

Brachial or Femoral Artery. The most helpful feature of the brachial arterial tracing was the 
TABLE

Essential hamodynamic Data in Both Types of Subvalvar Aortic Stenosis (CASES 1-6 Muscular, 7-16 DisCRETE)

\begin{tabular}{|c|c|c|c|c|c|c|c|c|c|c|c|c|}
\hline \multirow{2}{*}{$\begin{array}{l}\text { Case } \\
\text { No. }\end{array}$} & \multirow{2}{*}{$\begin{array}{l}\text { Sex } \\
\text { and } \\
\text { age }\end{array}$} & \multicolumn{4}{|c|}{ Pressures (mm.Hg) } & \multicolumn{3}{|c|}{$\begin{array}{l}\text { Systolic upstroke time } \\
\text { to highest peak (sec.) }\end{array}$} & \multicolumn{4}{|c|}{$\begin{array}{c}\text { Rate of initial rise of pressure } \\
(\mathrm{mm} . \mathrm{Hg})\end{array}$} \\
\hline & & LV & $\begin{array}{c}\text { Subvalvar } \\
\text { zone }\end{array}$ & Aorta & $\begin{array}{c}\text { BA } \\
\text { or FA }\end{array}$ & $\begin{array}{c}\text { Subvalvar } \\
\text { zone }\end{array}$ & Aorta & $\begin{array}{c}\text { BA } \\
\text { or FA }\end{array}$ & LV & $\begin{array}{c}\text { Subvalvar } \\
\text { zone }\end{array}$ & Aorta & $\begin{array}{r}\text { BA } \\
\text { or FA }\end{array}$ \\
\hline 1 & F 44 & $\frac{216}{8,25}$ & $\frac{77}{8}$ & $\frac{77}{53}$ & $\frac{95}{53}$ & 0.06 & 0.04 & 0.07 & 1080 & 880 & 680 & 850 \\
\hline 2 & F 34 & $\frac{150}{8,18}$ & $\frac{60}{8}$ & $\frac{55}{35}$ & $\frac{80}{50}$ & 0.13 & $0 \cdot 11$ & 0.04 & 650 & 430 & 875 & 1100 \\
\hline 3 & M14 & $\frac{243}{2,30}$ & $\frac{99}{2}$ & $\frac{99}{64}$ & - & 0.08 & 0.05 & - & 800 & 940 & 1370 & - \\
\hline 4 & M19 & $\frac{135}{20,25}$ & $\frac{85}{20}$ & $\frac{85}{60}$ & $\frac{100}{50}$ & $0 \cdot 14$ & $0 \cdot 12$ & 0.05 & 812 & 440 & 350 & 1500 \\
\hline 5 & M42 & $\frac{145}{0}$ & $\frac{70}{0}$ & $\frac{70}{54}$ & $\frac{75}{47}$ & 0.09 & 0.09 & 0.09 & 1250 & 1125 & 400 & 400 \\
\hline 6 & M37 & $\frac{165}{25,35}$ & $\frac{110}{25}$ & $\frac{110}{70}$ & $\frac{100}{50}$ & 0.08 & 0.07 & 0.07 & 1875 & 875 & 1250 & 940 \\
\hline 7 & F 30 & $\frac{168}{10,20}$ & $\frac{106}{15}$ & $\frac{100}{66}$ & $\frac{106}{60}$ & 0.35 & 0.28 & 0.07 & 1900 & 1900 & 930 & 1200 \\
\hline 8 & F 26 & $\frac{205}{15,28}$ & $\frac{120}{15}$ & $\frac{120}{70}$ & $\frac{150}{65}$ & 0.31 & 0.27 & $0 \cdot 13$ & 1815 & 1630 & 450 & 1050 \\
\hline '9 & F 22 & $\frac{145}{15,20}$ & $\frac{85}{15}$ & $\frac{90}{60}$ & $\frac{130}{60}$ & 0.37 & 0.32 & 0.26 & 1080 & 640 & 300 & 588 \\
\hline 10 & F 8 & $\frac{134}{10}$ & $\frac{90}{10}$ & $\frac{90}{77}$ & $\frac{100}{75}$ & 0.05 & 0.28 & $0 \cdot 19$ & 2000 & 2000 & 360 & 430 \\
\hline 11 & M17 & $\frac{186}{12,18}$ & $\frac{103}{12}$ & $\frac{103}{71}$ & $\frac{130}{75}$ & 0.31 & 0.23 & $0 \cdot 13$ & 1500 & 1500 & 550 & 800 \\
\hline 12 & M14 & $\frac{160}{7}$ & $\frac{85}{7}$ & $\frac{85}{60}$ & $\frac{75}{40}$ & 0.29 & 0.26 & 0.08 & 1625 & 1625 & 310 & 1800 \\
\hline 13 & M13 & $\frac{150}{8,12}$ & $\frac{112}{8}$ & $\frac{112}{78}$ & $\frac{112}{85}$ & 0.26 & 0.27 & $0 \cdot 19$ & 1875 & 1875 & 700 & 750 \\
\hline 14 & M 7 & $\frac{232}{5}$ & $\frac{86}{5}$ & $\frac{86}{55}$ & $\frac{86}{45}$ & 0.41 & 0.32 & $0 \cdot 11$ & 1625 & 400 & 375 & 480 \\
\hline 15 & M10 & $\frac{130}{20}$ & $\frac{65}{20}$ & $\frac{65}{50}$ & $\frac{100}{75}$ & 0.45 & 0.32 & 0.24 & 1250 & 625 & 250 & 265 \\
\hline 16 & M 9 & $\frac{155}{5}$ & $\frac{60}{0}$ & $\frac{60}{30}$ & $\frac{90}{45}$ & 0.40 & 0.20 & 0.07 & 1060 & 400 & 310 & 1185 \\
\hline
\end{tabular}

The ventricular diastolic pressures given are first the mid-diastolic value and then the value to the peak of the transmitted "a" wave where this was visible. 


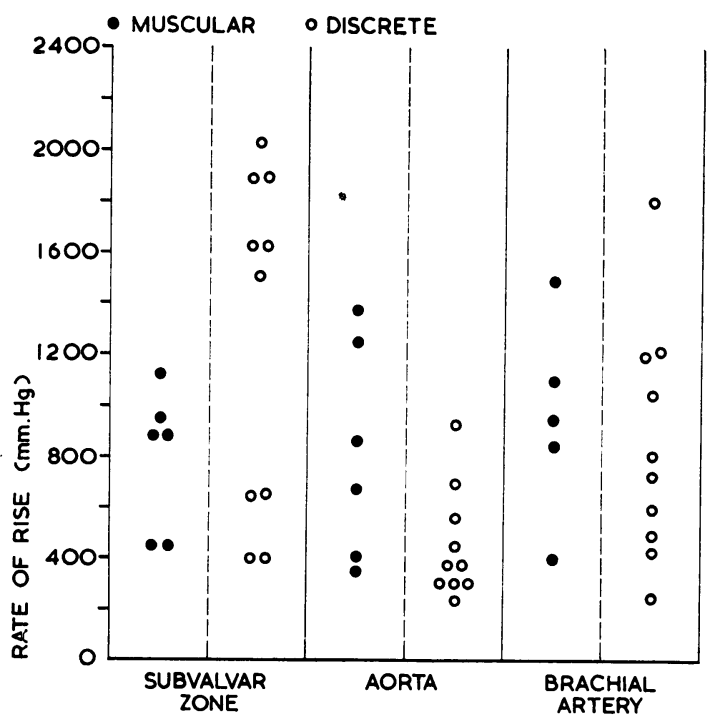

FIG. 1.- The rate of initial rise of pressure in the two groups in the subvalvar zone, aorta, and brachial artery.

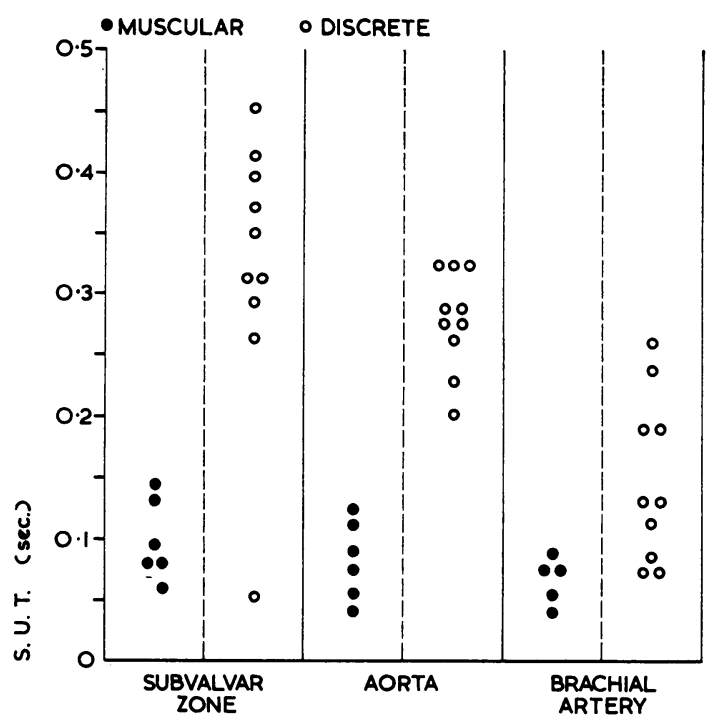

FIG. 2.-The systolic upstroke times in the two groups in the subvalvar zone, aorta, and brachial artery.

SUT. In the muscular type it ranged from 0.04 to $0.09 \mathrm{sec}$. in the 5 patients in whom an adequate peripheral arterial tracing was available. In the discrete group it lay between 0.07 to $0.26 \mathrm{sec}$. Assuming an SUT of $0.08 \mathrm{sec}$. or less as a feature of the muscular group, it would be accurate in 4 patients and inaccurate in 3. A rapid upstroke time would, therefore, appear to be a fallible criterion in the arterial pulse. Considering the rate of initial rise in pressure, this criterion is again seen to be fallible. There is almost complete overlap between the two groups, the values lying between 400 and $1500 \mathrm{~mm} . \mathrm{Hg} / \mathrm{sec}$. in the muscular and between 265 and $1800 \mathrm{~mm} . \mathrm{Hg} / \mathrm{sec}$. in the discrete group (Fig. 1).

Aorta. In the aortic tracings, the SUT was 0.04 to $0.12 \mathrm{sec}$. in 6 patients with muscular type. In the discrete type it was 0.20 to $0.32 \mathrm{sec}$. There is excellent separation between the groups in this respect (Fig. 2).

When the rate of initial rise of pressure in the aorta was assessed, there was considerable overlap between the two groups. The only two patients with a rate of rise of more than $1200 \mathrm{~mm} . \mathrm{Hg} / \mathrm{sec}$. in the aorta were both muscular, but 2 with muscular stenosis gave values of less than $500 \mathrm{~mm} . \mathrm{Hg} /$ sec. (Cases 4 and 5). In Case 4, the difference between the rates of rise in aorta and brachial artery are striking, the latter reflecting much better the nature of the lesion. In Case 5, both rates are relatively slow for the type of stenosis.

When a rate of rise of aortic pressure of $1200 \mathrm{~mm} . \mathrm{Hg} / \mathrm{sec}$. or more was taken to indicate a muscular and a rate of rise of $500 \mathrm{~mm} . \mathrm{Hg} / \mathrm{sec}$. or less a discrete lesion, the criterion was accurate in 9 and failed in 7 cases.

The analysis of the subvalvar chamber pressure tracing, as shown in the Table, allowed a distinction to be made between the two varieties with one exception.

Reproductions of the various subvalvar pressure curves are shown in Fig. 3 to 5, and the characteristic features are the following:

(1) Short systolic upstroke time to the highest systolic pressure in the muscular cases $(0.06$ to $0 \cdot 14 \mathrm{sec}$.).

In all the discrete cases with the exception of Case $10(0.05 \mathrm{sec}$.) a prolonged upstroke time to the highest pressure was seen $(0.22$ to $0.36 \mathrm{sec}$.). 


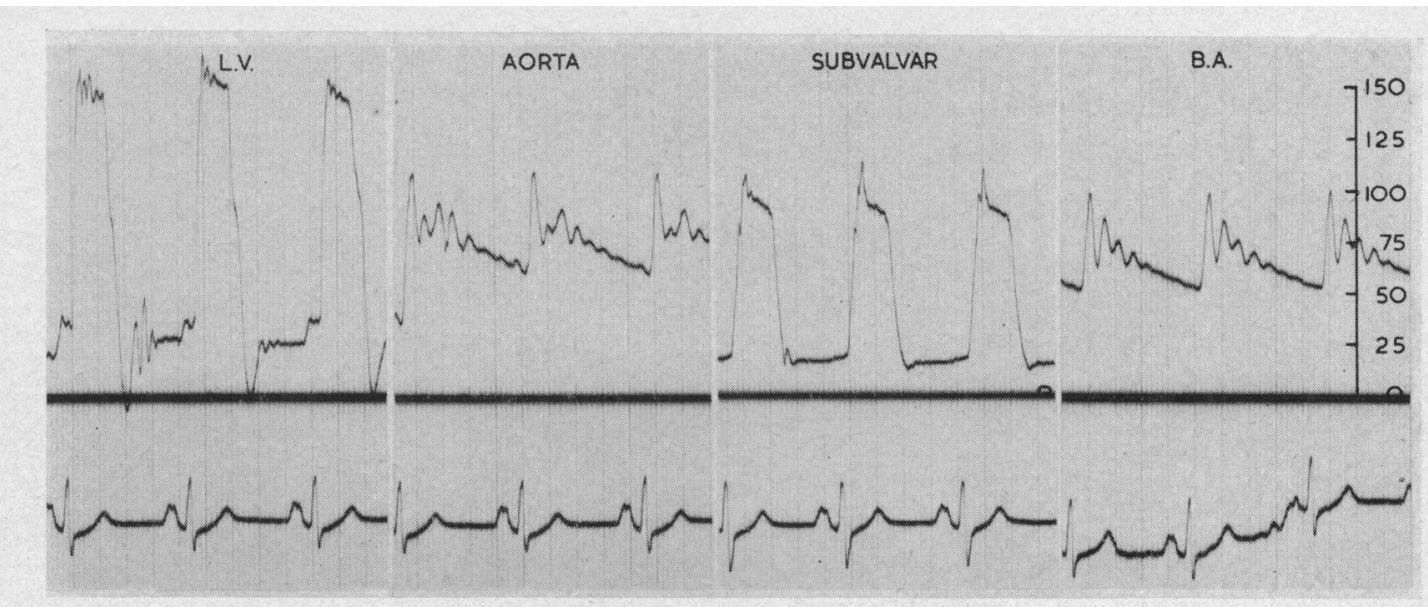

FIG. 3.-Tracing obtained in Case 6 (muscular) showing a rapid upstroke time in the subvalvar zone tracing as well as in the aortic and the brachial, where a high initial rate of rise of pressure is also present.

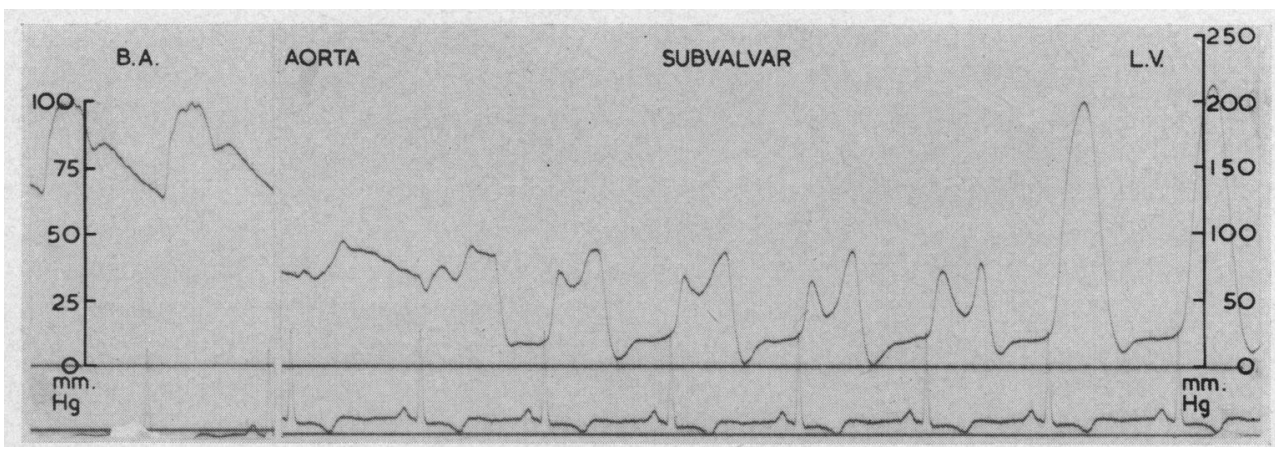

Fig. 4.-Tracings obtained in Case 9 (discrete). The late peaking of the subvalvar pressure, together with the presence of a deep systolic notch, are characteristic of the discrete lesion.

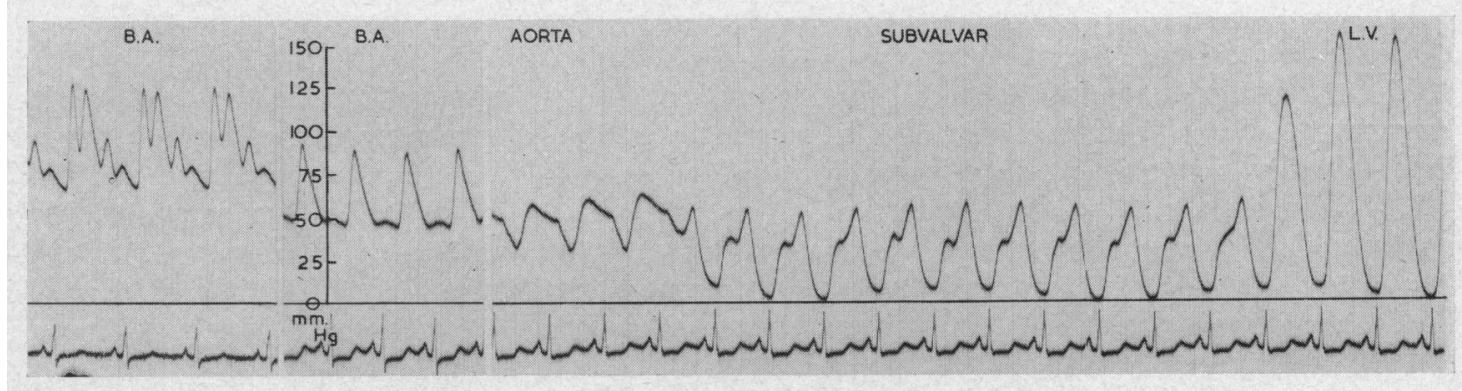

FIG. 5.-Tracings obtained in Case 16 (discrete). The brachial arterial pressure obtained on two occasions shows in both tracings a rapid upstroke time $(0.07 \mathrm{sec}$.) and a high initial rate of rise $(1185 \mathrm{~mm} . \mathrm{Hg} / 1 \mathrm{sec}$.) which suggest a muscular stenosis. Conversely the subvalvar tracing is in keeping with the diagnosis of discrete subaortic stenosis showing the prolonged upstroke time and the anacrotic notch which is not as deep and characteristic as in the other cases of the same group. 


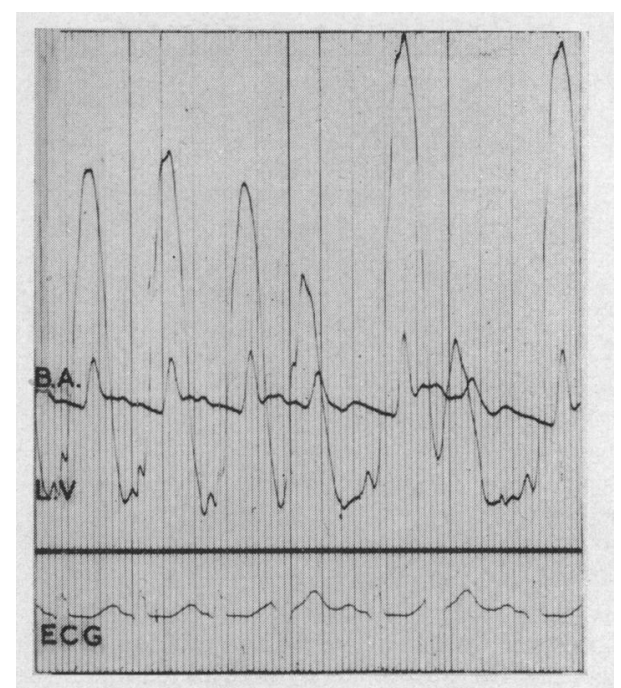

FIG. 6.-The behaviour of the post extrasystolic beat in Case 5 with muscular stenosis. Simultaneously recorded tracings of left ventricular and brachial pressures. The pulse pressure is increased in the systolic beat.

(2) A deep notch immediately after the percussion wave was noticed in all but one of the discrete but in only one of the muscular cases. This was a particularly useful criterion in one where the percussion and the tidal waves were of about equal height.

The changes in arterial pulse pressure following the compensatory pause after an extrasystole, as described by Brockenbrough et al. (1961), were observed where possible. Extrasystoles were present in 4 out of 6 patients in the muscular group, but a diminution of pulse pressure in the postextrasystolic beat was seen in only one of these. In the discrete type extrasystoles were seen in only 1 out of 10 patients, and in this one the pulse pressure behaved normally. The phenomenon therefore was helpful in only 1 out of the 4 patients with muscular stenosis where extrasystoles were present (Fig. 6).

\section{DisCUSSION}

Since Brock in 1957 first described functional obstruction to left ventricular outflow a number of papers have been published on this general topic. Many refer to the problem of the differential diagnosis between the two varieties of subvalvar aortic stenosis.

Brachfeld and Gorlin (1959) and Goodwin et al. (1960) drew attention to the significance of the arterial pulse contour. Several other reports followed (Hancock, 1961; Wigle, 1963; Boiteau et al., 1963), emphasizing the importance of several features of the arterial pulse, especially the rate of rise of pressure and the upstroke time. In the muscular variety a sharp upstroke is usually observed (Brachfeld and Gorlin, 1959; Goodwin et al., 1960).

Though a short SUT has been confirmed in this series as a feature of the brachial arterial tracing in the muscular group, it has also been present in 3 patients with discrete subaortic stenosis (Cases 7 , 12, and 16). No other recognized features were present to distinguish these 3 from the other members of the discrete group. At operation the obstruction in all 3 was found to be a pure fibrous diaphragm without any coexisting muscular element. The rate of initial rise of pressure was also rapid in these 3 (Fig. 5).

Thus the SUT in the peripheral artery was rapid in all 5 patients with muscular stenosis. In the sixth it was too damped to be valid. In the discrete group 3 of the 10 patients had a rapid SUT (less than $0.09 \mathrm{sec}$.), and $6 \mathrm{had}$ an SUT less than $0.13 \mathrm{sec}$. We do not think that the contour of the arterial pulse is of any help in differentiating between the diaphragmatic and fibromuscular 
types of fixed discrete subaortic stenosis. Previous observations (Hancock, 1961) depended on surgical evidence obtained from closed transventricular procedures in several cases. While pathologically three types of subaortic stenosis seem to exist (membranous or diaphragmatic, fibromuscular, and pure muscular), we have yet to be convinced that the arterial pulse contour in the fibromuscular group differs from that of patients with a diaphragmatic type of lesion, both being dominated by the fixed element. Amongst our patients with discrete lesions, 7 were described at operation as having a purely diaphragmatic or fibrous type of obstruction and 3 were of the fibromuscular type, where excision of the fibrous ring failed to relieve the stenosis, and either myotomy or muscle excision had to be performed. These fibromuscular cases do not differ in their hæmodynamic features before operation from those with the purely diaphragmatic lesion.

In all muscular cases the SUT was rapid in the central aortic pulse tracing. In the discrete group the SUT was prolonged in all patients. The rate of initial rise of pressure in the aortic pulse showed considerable overlap between the two groups, though less so than in the brachial tracing. In the discrete group all except one patient showed a value of less than $700 \mathrm{~mm} . \mathrm{Hg} / \mathrm{sec}$., and all except two less than $550 \mathrm{~mm} . \mathrm{Hg} / \mathrm{sec}$., whereas in the brachial pulse there was much more variation in these discrete cases.

In this series, therefore, the SUT in the aortic tracing was found to be a good differentiating feature between the two groups and, in contradistinction to the findings of Wigle (1963), was superior to the brachial. We must note, however, that there may be some variability in the contour of the aortic pulse depending upon whether it was obtained from a point close to the aortic valve or more distally, though there was little variation in the SUT in our cases between the tracings from different aortic sites.

In the subvalvar tracings two features are noteworthy. First, the upstroke time to peak pressure fails as a criterion in none of the muscular group and in only one (Case 10) of the discrete group, in whom the second feature helps to categorize the case. Secondly, there was a deep notch between the two peaks of pressure in all members of the discrete group, except Case 16, presumably because of the Venturi effect distal to the site of fixed obstruction.

The rate of rise of pressure in the subvalvar chamber is high in some patients with discrete stenosis (Fig. 1), and in 6 of them exceeded the highest value in any member of the muscular group. This criterion is of no diagnostic value.

The Brockenbrough et al. (1961) phenomenon, as already described, has in our series not proved very helpful, and moreover no help has been gained by using such other criteria as the anacrotic notch on the ascending limb of the left ventricular pressure tracing or the presence of pulsus alternans.

\section{SUMMARY}

The hæmodynamic features of 16 patients with subaortic stenosis have been examined, with particular reference to the form of the tracing from the subvalvar zone. The nature of the lesion was determined at open-heart operation or necropsy in 14 of these patients, and in the other 2 the strong family history and typical features leave no doubt as to the type of stenosis.

The subvalvar tracing is of considerable help in differentiating between muscular and discrete stenosis, the most useful features being a prolonged systolic upstroke time to the peak pressure, associated with a prominent systolic notch, in the discrete group. In the muscular group the systolic upstroke time is short and the systolic notch less marked. Taken in conjunction with the systolic upstroke time in the aorta, we have found these to be the most accurate differentiating features. The measurement of the rate of rise of pressure, particularly in a peripheral artery, has in this series been found more fallible.

Most patients were under the care of Dr. C. G. Baker and Dr. D. C. Deuchar at the time of catheterization. We are grateful to them for having allowed us to make use of the records.

The operations on these patients were performed by Sir Russell Brock, Mr. D. N. Ross, and Mr. I. M. Hill: we are indebted to them for their surgical reports. We would like to thank Mr. John Gwynn for help with the preparation of the tracings. 


\section{REFERENCES}

Boiteau, G. M., and Allenstein, B. J. (1961). Hypertrophic subaortic stenosis. Clinical and hemodynamic studies with special reference to pulse contour measurement. Amer. J. Cardiol., 8, 614.

-, Bourassa, M. G., and Allenstein, B. (1963). Upstroke time ratio. A new concept in differentiating valvular and subvalvular aortic stenosis. Amer. J. Cardiol., 11, 319.

Brachfeld, N., and Gorlin, R. (1959). Subaortic stenosis: a revised concept of the disease. Medicine (Baltimore), 38, 415.

Braunwald, E., Goldblatt, A., Aygen, M. M., Rockoff, S. D., and Morrow, A. G. (1963). Congenital aortic stenosis. I. Clinical and hemodynamic findings in 100 patients. II. Surgical treatment and the result of operation. Circulation, 27, 426.

Brock, R. (1957). Functional obstruction of the left ventricle; acquired aortic subvalvar stenosis. Guy's Hosp. Rep., 106, 221.

- Milstein, B. B., and Ross, D. N. (1956). Percutaneous left ventricular puncture in the assessment of aortic stenosis. Thorax, 11, 163 .

Brockenbrough, E. C., Braunwald, E., and Morrow, A. G. (1961). A hemodynamic technic for the detection of hypertrophic subaortic stenosis. Circulation, 23, 189.

Goodwin, J. F., Hollman, A., Cleland, W. P., and Teare, D. (1960). Obstructive cardiomyopathy simulating aortic stenosis. Brit. Heart J., 22, 403.

Hancock, E. W. (1961). Differentiation of valvar, subvalvar and supravalvar aortic stenosis. Guy's Hosp. Rep., 110, 1 .

Seldinger, S. I. (1953). Catheter replacement of the needle in percutaneous arteriography; new technique. Acta radiol. (Stockh.), 39, 368.

Wigle, E. D. (1963). The arterial pressure pulse in muscular subaortic stenosis. Brit. Heart J., $25,97$.

Wood, P. (1958). Aortic stenosis. Amer. J. Cardiol., 1, 553. 